\title{
Autism in the Twentieth Century: An Evolution of a Controversial Condition
}

\author{
Michelle O'Reilly, Jessica Nina Lester and Nikki Kiyimba
}

\section{INTRODUCTION}

Clinically, autism spectrum disorder (henceforth, autism) has been described as a lifelong neurodevelopmental condition characterised by impairments in social interaction, communication, and rigidity in thinking. Additionally, autistic individuals are typically characterised as having executive functioning difficulties (i.e. self-regulation skills), sensory processing problems (i.e. the brain processing information from the senses), difficulties with sleep and food, limited theory of mind (i.e. the ability to see things from the point of view of others), and the possibility of various co-morbid mental health conditions. ${ }^{1}$ Despite such descriptions,

\section{O’Reilly $(\bowtie)$}

The Greenwood Institute, University of Leicester, Leicester, UK e-mail: Mjol4@le.ac.uk

J. N. Lester

Indiana University, Bloomington, IN, USA

e-mail: jnlester@indiana.edu

N. Kiyimba

University of Chester, Chester, UK

e-mail: n.kiyimba@chester.ac.uk

(C) The Author(s) 2020

S. J. Taylor and A. Brumby (eds.), Healthy Minds

in the Twentieth Century, Mental Health in Historical Perspective, https://doi.org/10.1007/978-3-030-27275-3_7 
autism, as we now know it, is a relatively new condition. In less than a century, a whirlwind of ideas, movements, and positions have littered the autism literature, with a critical polemic threaded through the narratives of various autistic individuals, political advocates, writers, and academic scholars. Indeed, autism is a by-product of many (even conflicting) disciplinary knowledges, institutional discourses, and histories. ${ }^{2}$

The twentieth century was a significant and powerful century for autism, and for some, it has been classified and understood as a 'twentiethcentury disorder' ${ }^{3}$ Not only were there clinical advances in terms of it being recognised, labelled, and identified and appearing in the classification systems for mental illness, but there was also the rise of pharmacology for treatment and the increased role of psychiatry for identifying and managing autism. Importantly, the twentieth century also saw a rise of critical rhetoric, challenges, political ideologies, and a range of movements, such as anti-psychiatry, critical psychiatry, neurodiversity, consumerism, and social models of disability. All these movements and perspectives made visible a struggle to invent, reconfigure, and reinvent the meaning of autism, with some challenging the position of autism as a mental health difficulty, that is, a psychiatric disability. Indeed, even in the historical present, the classification of autism as a mental health condition is controversial and contested. Later in the twentieth century, autism became redefined as a spectrum, which served to acknowledge the great heterogeneity within the meaning of autism and developed more refined ideas around the so-called impairments associated with it.

In this chapter, we overview some of the historical changes and, in doing so, highlight some challenges of labels and language that shroud those who are named autistic and/or take up this identity label. We also note the shifts in thinking that have challenged the psychiatric and psychological framing of autism. The residue of the twentieth-century tensions that is the genetic revolution, the diagnostic medicalisation, and the empowerment of neurodiversity has spilled over into the twenty-first century, leaving us with an array of critical discourses and challenges around what many now describe as a spectrum condition. That is, we are left with a patchwork of different perspectives and ideas regarding what constitutes autism, the language of autism, how autism should be researched, and the most appropriate healthcare pathways and other service provisions for those diagnosed. This chapter explores how this fractured view of one 'mental health difficulty' came to be. In so doing, we thread through our own position, that of social constructionism, not denying the reality of the autistic community, but acknowledging 
differences in views and the importance of language and meaning. Indeed, we recognise that for some autism is celebrated, treated as difference, and tensions of medical notions and impairments are proposed, and yet for others, autism is seen as disabling, the diagnosis is stressful, and treatments are actively sought. The range of perspectives that grew from the twentieth century are considered throughout. We do however insert a caveat here and note that the history of autism is vast and spans multiple disciplines and fields, and thus what follows can only ever represent a snapshot of history and inevitably misses out some of the developments that occurred throughout that century and some scholarly contributions. The chapter is only ever intended as a summary.

\section{EArly History of Autism}

Importantly, the concept of autism did not specifically exist prior to the 1940s, although the notion was introduced by Bleuler in his work on schizophrenia in 1911. However, it was the work of two pioneering practitioners that identified some of the core characteristics that distinguished it as a discrete concept. First, the work of Leo Kanner, following his seminal child psychiatry text in 1935, introduced the world to the condition, autism. ${ }^{4}$ Kanner was an Austrian psychiatrist who wrote a paper describing the behaviour he had observed in eleven children. He conceptualised these characteristics as a need for sameness, aloneness, and obsessions. It was common at this time for children with these types of behaviours to be classified as schizophrenic, so Kanner's work was important for distinguishing between the two groups. However, it should be noted here that the credit given to Kanner has created some tension and criticism. ${ }^{5}$ Second, was the work of Hans Asperger who was writing in parallel with Kanner and wrote about the characteristics of children in similar ways. ${ }^{6}$ Asperger was a German paediatrician who observed the behaviour of four boys who he argued were showing challenges in forming friendships, displayed a general lack of empathy towards others, had clumsy movements, and had difficulties with communication. While this work became considerably influential, it did not reach the mainstream literature until after he died. It was Asperger who noted that children with this syndrome could flourish, and in some cases show signs of genius, and expressed the insight that autism may exist on a continuum. ${ }^{7}$ It was this notion that resurfaced, as British psychiatrist Lorna Wing introduced the notion of a spectrum. ${ }^{8}$ 
Kanner and Asperger laid a foundation therefore for understanding the behaviours of these children, and Kanner particularly argued that no single factor could explain it. However, the influence of psychoanalysis was strong during this time, and therefore, there was also a powerful promotion of the idea that there were psychodynamic causes. ${ }^{9}$ This domination of psychoanalytic theory at this time formed the basis of a culture that blamed mothers for their child's psychological problems. ${ }^{10}$ A hugely influential theory in the 1960s, long since discredited, was that autism was associated with a certain style of parenting, with a cold and unavailable mother leading the child to shut down emotionally. ${ }^{11}$ Bettelheim referred to this as the "refrigerator mother'" 2 and resulted in many mothers feeling to blame for their child's condition. This has been argued to be particularly problematic, given that evidence suggests that Bettelheim faked his medical credentials. ${ }^{13}$

Nonetheless, there is some persistence of mother-blaming even today, ${ }^{14}$ despite the neurodevelopmental positioning of autism ${ }^{15}$ and despite the extensive criticism. ${ }^{16}$ Historically it has always been women who have carried this parental burden, as they were argued to fail to conform to the idealised view of motherhood. ${ }^{17}$ There was a shift in thinking as psychoanalytic views lost some favour, and science took over as the predominant explanatory framework, and yet the blaming rhetoric underwent a subtle shift as mothers were not blamed via their parenting skills and style, but via their genes. The genetic and medical revolution in psychiatry positioned the aetiology of autism and other mental illnesses as having a biological origin. ${ }^{18}$ This is something we return to shortly.

\section{Contextualising Children}

An important advancement during the first half of the twentieth century that has important implications for the development of an understanding of autism was the view of children and childhood in relation to the role of psychiatry and psychology. As Steve Taylor observes in Chapter 4, a significant period of history for child mental health was the introduction of a universal education system. In Europe and North America in the late nineteenth century, there was a new formalisation of public and private education. ${ }^{19}$ Karim reported that it was this formalisation of education that provided a platform for adults to recognise physical and mental health conditions in the young, which subsequently in the twentieth century led to the creation of sub-disciplines such as educational psychology, 
social care, and developmental psychology. The increase in the social surveillance of children with the advent of compulsory education indeed engendered the necessary social conditions for the creation of autism. ${ }^{20}$ Further, developmental psychology was especially influential and is generally credited as beginning with the work of Wilhelm Preyer in 1882 and G. Stanley Hall through his introduction of the first American Journal of Child Psychology in 1891. ${ }^{21}$ Notably, such work at the time, into the early twentieth century was heavily influenced by the notion of the 'normal' child, underpinned by psychoanalytic ideas of childhood, which was strengthened by the specialised work of Anna Freud, Melanie Klein, and Jacques Lacan, amongst others.

The field of psychiatry also recognised the relevance and importance of treating children separately from adults, and it was in 1935 that the first child psychiatry textbook was produced by Leo Kanner. This was in parallel with the US work by Douglas Thom who developed the Boston Habit Clinic designed to help parents manage their child's everyday difficulties. This was considered necessary as following the Second World War there was recognition that children too needed help with their mental health. ${ }^{22}$ Child psychiatry therefore became a separate sub-discipline of medicine, and one that recognised that specialist attention that was developmentally appropriate was needed, with the foundation of the American Academy of Child and Adolescent Psychiatry happening in 1953. ${ }^{23}$ By the 1960s and 1970s, therefore, specific treatments designed for children had been developed within psychiatry and psychology. ${ }^{24}$ Furthermore, during this period, family therapy emerged and gained popularity as it viewed the child as part of a complex social system. ${ }^{25}$ However, it was the focus on pharmacological treatments for children that raised controversy in the later part of the twentieth century and continues today. ${ }^{26}$ Thus, by the late twentieth century, child mental health was treated as distinctive and separate by a range of health services, including psychiatry, nursing, psychology, and education. Such services for children relied on childhood being constructed as a series of stages, with a separate focus on adolescence.

\section{Diagnosing Autism: The Introduction of Standardised Manuals}

A crucial historical moment in conceptualising autism was the development of standardised manuals. We present an overview of the main diagnostic manual, the Diagnostic and Statistical Manual of Mental Disorders (DSM) 
to demonstrate some of the key shifts in thinking about autism. While we recognise that there was some influence of the International Classification of Diseases (ICD), this system was much broader and contained physical illness, whereas the DSM was designed specifically for mental illness. The DSM was designed so that those working in the field of mental health were able to classify the full range of mental health conditions based on standardised criteria for diagnosis. ${ }^{27}$ In other words, the DSM defined what does and does not constitute an illness and by default implies what constitutes normality and therefore a 'healthy mind'. 28

The development of the DSM and the role of psychiatry have to some extent influenced how 'normal' is viewed, and the American Psychiatric Association decided to unify the diagnostic processes with the creation of DSM-I. Notably, however this single manual was not published until 1952. ${ }^{29}$ This first edition represented an important paradigmatic change about the conceptualisation of mental illness and was a milestone in the creation of diagnostic categories. This first version contrasted two core groups of conditions, those caused by organic brain dysfunction and those with aetiology in environmental circumstances. ${ }^{30}$ The second version, DSM-II, was developed quite quickly because of concerns about inconsistencies in the first. This version had 193 diagnostic categories, was heavily influenced by psychoanalysis, and launched in $1968 .^{31}$ This version of the DSM transformed psychiatry from a field that was concerned with pathology, to one that was more concerned with the boundaries of normality. ${ }^{32}$ During this time, the rise of psychopharmacology was influencing more biological and neurological explanations of mental illness. Consequently, the diagnostic criteria were proposed as ways to ensure that standardisation could be achieved. ${ }^{33}$

The notion of standardisation underpinned new changes to the system, and in the resulting DSM-III, there were substantial changes from DSM-II. DSM-III contained criteria which identified categories but moved to a multi-axial system for diagnoses, ${ }^{34}$ and while the revision began in 1974, it was not published until 1980. ${ }^{35}$ This version held nearly 500 pages and 265 categories. $^{36}$ The USA was especially influential here with its insurance health system, as they demanded more precise diagnostics and were more reluctant to fund long-term therapies like psychotherapy. ${ }^{37}$ What is especially relevant to our discussion in this chapter is that it was the advent of DSM-III in 1980 that recognised autism as a distinct conceptual category, almost 40 years after its inception by Kanner. ${ }^{38}$ 
It was this point in the twentieth century, with the inclusion of autism on the DSM-III that the work of Kanner and Asperger were revived by two British professionals who coined the notion of autistic spectrum disorder $^{39}$ and the triad of impairments became part of common clinical discourse. ${ }^{40}$ This triad consisted of three core characteristics of autism;

1. Impairments in social interaction

2. Impairments in communication

3. Restrictive repetitive patterns of behaviour.

This was later reconfigured in the twenty-first century as a dyad of impairments and reconstructed as autism spectrum disorder, but the notion of the spectrum has been maintained.

A quick succession of revisions occurred after this with DSM-III- $R$, to DSM-IV, and DSM-IV- $R$ which each reflected a round of changes. Again, relevant to our discussion, is that DSM-IV saw the inclusion of Asperger's Syndrome and this was viewed as distinct to autism. ${ }^{41}$ Those with Asperger's Syndrome were seen as having normal or higher levels of intellectual ability, and those with the diagnosis often argue that this is fundamental to their identity. ${ }^{42}$

\section{DSM 5: Autism in the Twenty-First Century}

DSM-5 is the first of the manuals in the twenty-first century and reflects the modern revision from DSM-IV- $R$. Notably, this version was represented with numbers rather than Roman numerals. This new version, DSM-5, has created a great deal of controversy and was created during a period of critical thinking around mental illness more generally. The development of DSM-5 began at the end of the twentieth century and unlike its predecessors was subject to public scrutiny because of the rise of the internet. ${ }^{43}$ By 2010, the first draft was posted online and returned over 8000 comments, with 2000 further comments in 2011 on the revision. ${ }^{44}$ By this point, the DSM had grown to 947 pages and 541 diagnostic categories. ${ }^{45}$

This new version of DSM had some important changes for autism. While the notion of the spectrum was maintained, other changes were more controversial. For example, this version saw the removal of Asperger's Syndrome as a distinct classification. Indeed, Asperger's Syndrome had a short shelf-life in terms of official diagnosis, as it was 
not formally recognised until the 1990s and was then removed in 2013, being subsumed under the general category of autism spectrum disorder. The rationale for its removal was to reflect the shift from a categorical system to a dimensional one. ${ }^{46}$ This however has caused great unrest in the autistic community, ${ }^{47}$ as new interest groups have emerged claiming that classifications are a blueprint for their identity and not just an arbitrary means for classifying conditions. ${ }^{48}$

The criteria for diagnosing autism also shifted, as there was a move away from a triad of impairments, to a dyad of impairments, as we noted earlier. Thus, there were now just two domains of difficulties-social communication and restrictive and repetitive patterns of behaviour. ${ }^{49}$ However, Wing et al. argued that there were relevant clinical reasons why social interaction and communication were treated separately on the triad, and therefore, collapsing them into one domain was viewed as inappropriate. 50

The shifts in diagnosis and classification from the original version in 1952 to the latest version in 2013 have shaped and impacted on the meaning of autism and the language used to describe it. Autism is a condition that has invoked a great deal of debate and controversy in terms of the language and labels used and adopted and this has not been straightforward. As Kenny et al. noted,

Tensions surrounding the language of autism are attributable, in part, to the very different ways that autism touches people's lives; some experience it personally, others through their children and others still might only encounter autism in some aspect of their lives - at school, at work, in the community or through friends and family. ${ }^{51}$

The terms used and the language adopted around autism have changed over time, with a range of different conceptualisations of the condition, including, autism, autistic spectrum disorder, autism spectrum disorder, autism spectrum condition, Asperger's syndrome, pervasive developmental disorder, and high functioning autism. ${ }^{52}$ The different labels used are loaded with category rich inferences, and these can have different meanings for different individuals and their families.

The tensions and debates within public and academic communities regarding the most appropriate ways to conceptualise autism has been a consequence of growing disquiet about the role of psychiatry and the influence of medicine, as well as the rise of critical perspective. ${ }^{53}$ During 
the twentieth century, there was a shift towards person-first language when describing individuals diagnosed with autism, so that the person came first, and the disability came after, that is, person with autism. ${ }^{54}$ Over time however, this position has changed and further controversy about descriptive language has been proposed. Disability-first language is now more generally accepted to be the most appropriate way of describing autism, that is, an autistic person. This is because disability-first language adheres to the principle of putting a positive pronoun in front of the noun and thus removes the suggestion that autism is intrinsically negative. ${ }^{55}$ This is especially important for the autism community who often view their autism as an accepted and instrumental part of their identity. ${ }^{56}$ A good example of this was offered by Hagan who argued that society would not describe someone who was creative as 'a person with creativity', they would be a creative person and as such treats the creativity as part of who they are ${ }^{57}$ Perhaps unsurprisingly then, research has shown that diagnosed individuals tend to favour the concept of 'autistic person', but interestingly professionals still favour 'person with autism' ${ }^{58}$

\section{The Genetic Revolution}

An important contribution to the rise of science and medicine was advances in the study of genetics. Psychiatry and medicine advocated organic causes of mental illness, and geneticists began to seek ways to isolate the gene(s) responsible for autism. This notion of aetiology had important implications for how we view autism and for the position of autistic people in society. The geneticisation of deviance worked to provide accounts for behaviour that failed to conform to social norms and thus provided new ways of thinking about stigma. ${ }^{59}$ In other words, those with diagnosed conditions were now constructed as less blameworthy for their condition where it had a biological origin rather than a psychosocial one. ${ }^{60}$

Such a turn to science has had consequences for research and funding. The field of autism research became reenergised by genetics studies. This generally increased pace in the late-1990s, when a link between two chromosomes, $15 \mathrm{q}$ and $7 \mathrm{q}$, were identified as connected to autism. ${ }^{61}$ Consequently, large funding streams have been provided to further the credibility of genetic explanations, so that the aetiology may be uncovered, and medical treatments created that target the core 
symptoms. However, it is arguably concerning that this energy has resulted in a dominance of genetics in the study of autism at the expense of other kinds of necessary and needed research. Statistics from the UK have shown that autism research is now preoccupied with biomedical issues, as $56 \%$ of studies have explored brain, biology, and condition, and a further $15 \%$ on aetiology, and only $18 \%$ on interventions, $5 \%$ on services, and $5 \%$ on diagnosis. ${ }^{62}$ The picture is similar in the USA, which spends 18 times the amount of the $\mathrm{UK}$, but again biologically grounded work receives significantly greater income than other areas. ${ }^{63}$

The inappropriateness of this lack of balance in research funding streams has been positioned from a range of different views. For example, some have argued that autism is an incredibly complex and heterogeneous condition, and it is unlikely that scientists will be able to isolate a single autism gene. ${ }^{64}$ Arguably more concerning is the risk or threat perceived by the autistic community in terms of the potential for genetic testing, which may put mothers under pressure to terminate their pregnancy. ${ }^{65}$ Waltz noted that for autism this is especially concerning as the spectrum is broad and it is likely that multiple genes are connected, and this termination potential may threaten the lives of autistic people who could be functional in society. Some scholars have extended this argument further by claiming that the genetic focus in autism research reflects a new wave of eugenics. ${ }^{66}$

The diversion of research resources to genetics research is also problematic for those already diagnosed as autistic. Critics and autistic advocates have argued that by prioritising genetics research, necessary finances have been diverted away from those who need support now. ${ }^{67}$ Arguably, there is a need for more research which focuses on the agendas that matter to autistic people and their families. ${ }^{68}$ In our own work, we found that genetics research and the notion of a cure for autism was a low priority for autistic people and their families, and what they really wanted was more work to help them manage difficult behaviour, challenging sleep patterns, coping with adversity, and improving quality of life. ${ }^{69}$ The research base that has an impact on the lives of autistic people and their families is insufficient, and medical and genetic evidence is inconclusive or contested. ${ }^{70}$ It seems therefore that the priorities of medical researchers and funding councils are at odds with autistic self-advocates and families. ${ }^{71}$ In practice, this means there is a gap between our knowledge and practice, and we need to advance our research to meet the needs of those who would benefit from it most, by focusing on issues that affect people's daily lives. ${ }^{72}$ Specifically, we argue 
that there is a need for much more qualitative research that promotes the need to listen to the voices of autistic people and their families and allows for an exploration and focus on their views, opinions, and experiences.

\section{The Challenge of Anti and Critical Psychiatry}

The dominance of genetics and medicine in the field of autism has caused tensions for scholars and advocates throughout the twentieth century and into the twenty-first. As the different versions of the DSM evolved and changed, and the dominance of genetics and pharmacology grew, there was a notable shift in thinking about psychiatry as a discipline, the conceptualisation of mental illness (and more specifically tensions in classifying autism that way), and the ways in which diagnosed individuals ought to be treated and embedded in society. By the mid-twentieth century, there was a great deal of tension regarding the turn to science and medicine for answers regarding mental illness, and questions were raised about the credibility of categorising illness purely in biological ways and treatment with medications. Notably, movements during this latter half of the century were the anti-psychiatry and the critical psychiatry movement, which gained momentum as new and different critical arguments emerged.

It was during the 1960s that the international anti-psychiatry movement was recognised as such, as was a term coined by David Cooper. ${ }^{73}$ This movement was noted to be motivated by anger and the perceived arbitrariness of diagnosis. ${ }^{74}$ Those advocating anti-psychiatry called for a paradigm shift in terms of understanding mental illness and argued that patients were being marginalised. ${ }^{75}$ Fundamentally those taking this position opposed the use of medication, which was the main form of treatment in the field. Furthermore, they opposed the power of psychiatrists and considered the practices to be coercive (see, e.g., Foucault). ${ }^{76}$ The mid-twentieth century therefore saw three critical periods of antipsychiatry, as noted by Furnham:

1. The early 1950s, where there was a conflict between psychiatrists adopting psychoanalytic perspectives and those new ideas around biology.

2. The 1960s saw a range of influential figures, such as Szasz, Basaglia, Foucault, Laing, and Cooper, from within and outside of psychiatry. 
3. In the 1970s and 1980s, American and European sociology joined the debate, particularly in relation to labelling ideas and stigma, and popular media began to spotlight the practices of the profession. ${ }^{77}$

It was thus during the 1980s that anti-psychiatry began to lose its momentum, as psychiatrists began responding to the critique, changing their practices, and working in a more biopsychosocial way. This biopsychosocial perspective of formulating and working with mental illness began to address some of those concerns about treatment of the mentally ill. ${ }^{78}$ Thus, anti-psychiatry as a movement failed to establish itself as a mainstream ideology embraced by mental health professionals. ${ }^{79} \mathrm{~A}$ further paradigmatic shift occurred therefore in the 1990s, with a softer critique of psychiatry emerging under a new guise of critical psychiatry. ${ }^{80}$ The notion of critical psychiatry was coined by David Ingleby through the collection of essays into a monologue. ${ }^{81}$ This recognised the change from focusing on the institution to the community but retained recognition of the difficulties of psychiatry and the political issues surrounding the field. This movement began to gain some acceptance, even amongst those practicing psychiatry. ${ }^{82}$

The focus for critical psychiatry was that psychiatry was a powerful field, and this should be moderated by the voices of service users as central to decisions made. ${ }^{83}$ This movement thus proposed two core issues with psychiatry. First, they argued that there are challenges to the scientific basis of psychiatric classification, and second, they noted moral problems that are a consequence of diagnosis. ${ }^{84}$ The reliance on science and the turn to genetics were viewed as fundamentally problematic, as the biological basis of mental illness was argued to be overstated as the evidence fails to offer sufficient support for this thesis. ${ }^{85}$

One of the core concerns in the rising movements that had varying degrees of opposition to psychiatry, particularly from those concerned with autism, was that mental illness, and in this case autism, was being over-medicalised and thus ignoring the ecological and systemic frameworks around an individual. The significantly progressive number of diagnostic categories with each version of the DSM was argued to be increasingly medicalising behaviour of individuals, reducing social expectations of normal behaviour. ${ }^{86}$ Such an increase of conceptualisations of abnormality created by diagnostic manuals is a cause for concern, particularly in the context of autism, and the medicalisation of autism has been especially contested. 
The concept of medicalisation refers to the process of human experience being reduced to medical terms and definitions. ${ }^{87}$ It is this medical vocabulary that validates professionals' determination of what constitutes sickness, and who qualifies as being categorised as psychiatrically disabled. ${ }^{88}$ For the critical psychiatrists, psychiatry is a discipline that medicalises the mind as a way of legitimising the requirement of medicine to manage conditions ${ }^{89}$ and this perpetuates an illusion that medicine provides a theoretically viable view of disability, which in turn, is tied to the notion of recovery and the restoration of the healthy mind..$^{90}$ In other words, this perspective constructs the person's illness as dispositional, and those who are unable to be 'fixed' by medicine are inappropriately labelled as deficient in some way. ${ }^{91}$ Such a goal of normalisation denies agency to those with disabilities ${ }^{92}$ and risks judgements of laziness, weakness or belligerence. ${ }^{93}$ By the end of the twentieth century, healthcare was seen as consumer-driven and patient-centred, and these changes increased the tension between rising medicalisation and increased resistance to it. $^{94}$ Furthermore, the DSM-5 was argued to rely more heavily on medicalisation than any of its predecessors, ${ }^{95}$ because of lowered thresholds, which separate individuals from the optimal society. ${ }^{96}$

For autism, these arguments are especially pertinent. The autism diagnostic process lacks definitive measures, and while there are tools to facilitate the process, the decision relies mostly on the subjective judgement of professionals applying the criteria, and thus, the power of medicine to define, diagnose, and treat autism has come under criticism. ${ }^{97}$ There is therefore an extensive literature that expresses dissatisfaction with the medicalisation of autism as failing to adequately meet the needs of the autistic community. ${ }^{98}$ This has been further hindered by the medicalised notions of deficit and cure, as medicalisation has encouraged the search for a cure. ${ }^{99}$ Through this, autism has been constructed as a biological fact ${ }^{100}$ and the social and cultural aspects inherent to the language of autism have been given less attention. ${ }^{101}$ Consequently, autistic people and their families are frequently renegotiating what constitutes normal behaviour and such deviations from the norm are called to account. ${ }^{102}$

The ambition to 'fix' disability is central to medicalised practices, and for many autistic people, this provides a perspective that they are 'broken' in some way. ${ }^{103}$ Such ideas are co-constructed by the mental health profession and taken directly from medical, psychological, neurological, and developmental positions of autism as grounded in the criteria created through DSM-5. ${ }^{104}$ Importantly, autistic individuals do 
not use the same knowledge spheres or frames of reference as professionals, and their relationships with services can be stressful and in some cases conflicting. ${ }^{105}$

It may seem that medicalisation as a concept is negative; yet, notably medicalisation is not inherently problematic. The view of medicalisation as being viewed as good or bad rests on the implicit definitions of health and illness and a critical perspective regarding the effectiveness of medicine to address the well-being of the individual. ${ }^{106}$ Indeed, the founders of medicalisation theory, such as Peter Conrad, described medicalisation as value neutral. ${ }^{107}$ Furthermore, it must be recognised that medicalisation does serve some function for patients and families. It provides a basis to legitimise concerns that may otherwise be dismissed, and although there are risks that society takes on psychiatric concepts as identity terms, access to support largely relies on medics to confirm the nature of the problems. ${ }^{108}$ Thus, the medical hegemonic position on autism underpins a legislative requirement to access services, as without an official diagnosis and label families are not entitled to help. ${ }^{109}$ The flip side to this, however, is that parents may fear that if they fail to follow medical advice they will be morally implicated in any later negative experience. ${ }^{110}$

Despite the value neutral nature of medicalisation, it has brought with it a very particular orientation to mental health; that is, one focused on 'fixing' the presumably 'broken' individual. In contrast to this, more social constructionist understandings afford nuanced and layered understandings of difference and disability. More particular to autism, there is a need to shift away from a focus on the medicalisation to language, with its overreliance on medical explanations regarding autism. ${ }^{111}$ Such an overreliance might lead to the mismeasurement of the autistic experience. ${ }^{112}$ Indeed, this shift has implications for whether autism might be viewed as a natural identity or a dilemma. ${ }^{113}$ This focus on language and the social construction of disability and normal identity were encapsulated by a related movement, that of neurodiversity.

\section{Neurodiversity: Empowering Autism}

The language that we use has the power to reflect and shape people's perceptions of autism. ${ }^{114}$

A core focus of the neurodiversity movement is on the language we use around autism. This movement rejects medicalised negative concepts 
such as 'disorder', 'deficit', and 'impairment' and instead reconstitutes autism as a way of being. ${ }^{115}$ The neurodiversity movement therefore directly challenged framing autism in a medicalised way. The notion of neurodiversity can be traced to Australian sociologist Judy Singer and journalist Harvey Blume, and it became popular with civil rights groups in the late-1990s. ${ }^{116}$ The popularity of neurodiversity as a movement arose mostly online in response to what was argued to be a marginalisation of autistic people. ${ }^{117}$ Thus, this movement sought to establish a culture where autistic people could have pride in their autistic identity and provide mutual support in self-advocacy. ${ }^{118}$

An underpinning principle of neurodiversity was the foundational idea of a 'differently wired brain'. 119 This movement has been instrumental in advocating strength-based discourses for autism, ${ }^{120}$ but also for other brain-related conditions. ${ }^{121}$ For autism, neurodiversity has two main claims as outlined by Jaarsma and Welin:

1. That autism is simply a natural variation in humans, and being neuro-diverse or neurotypical, reflect different ways of being human.

2. That neurodiversity connects to human rights, political issues, and non-discrimination of autistic people. ${ }^{122}$

This movement therefore became associated with the struggle for civil rights for those individuals diagnosed with neurodevelopmental conditions $^{123}$ and as such became a counter-argument for the deficit model to prevent discrimination. ${ }^{124}$ This is important, as society tends to be organised around neurotypical values and by contrast autism is positioned as a deficit. ${ }^{125}$

As will be seen in Chapter 8 , an important aspect of neurodiversity is that the autistic community were instrumental in its promotion and development. Indeed, there are many autistic self-advocates who have celebrated autism as part of their identity and see their autism as a natural variation. ${ }^{126}$ Some of these people have expressed fears that the seeking of a 'cure' may result in the eradication of autism. ${ }^{127}$ It was argued therefore that by constructing autism as synonymous with impairments, it raises questions about what it means to be human, and those failing to conform to the dominant ideology are positioned as impaired. ${ }^{128}$

We would note here that not all those in the autistic community advocate a neuro-diverse position, and it is important to have some balance in these arguments. Some neurodiversity movement advocates have 
acknowledged that some aspects of autism can cause distress and their amelioration or control is sometimes useful, and they do not oppose all forms of intervention and treatment. ${ }^{129}$ Notably, some parents of children with autism do actively pursue treatments for their child and may even seek a cure for the condition. ${ }^{130}$ Parents of course should have the right to seek early intervention for their offspring and have the freedom to work in ways they see as best for their child. ${ }^{131}$ For those promoting neurodiversity, there is a position of promoting well-being and adaptive functioning to support autistic people. ${ }^{132}$ The balance therefore is to support the notion for treatment, support, and services to overcome some of the potentially disabling effects of the condition, while steering away from medicalisation, negative language of deficiency, and damaging stereotypes that reify difference. ${ }^{133}$ Neurodiversity as a movement and the construct of an autistic disability do not have to be incongruent, as individuals may have areas of strength and celebrate their identity, while still having some difficulties. ${ }^{134}$

A central underpinning concern that has arisen from medicalisation and from neurodiversity therefore is the way in which autism is classified. While medicalisation advocates the appropriateness of autism as a mental health condition, as reified through its presence on the DSM, neurodiversity tempers this position, critically questioning the 'deficit' associated with such constructions. Ultimately, therefore, questions have been raised as to whether autism should be viewed by medicine, and by society more widely, as a psychiatric disability. The rise of the neurodiversity movement in the latter part of the twentieth century had a significant impact on the way we view autism and contributed greatly to this debate. The construction of autism as a psychiatric category, as a mental health condition, and as a disability is therefore dependent upon different points of view, different theoretical frameworks, subscription to different disability models, and personal experiences and viewpoints.

In our own work, we attempt to strike a balance between recognising the real distress of some families and the severity of symptoms for some children, against the critical and imperative challenges to the notion of deficit and the importance of empowering autistic people. It is important to be aware that for some families the diagnosis of autism is stressful, and the condition can have some disabling effects on the autistic person and their families. ${ }^{135}$ For others, a more positive view of autism is necessary and the language surrounding the autistic identity is crucial in challenging deficit, stigma, and unacceptable stereotyping. Arguably, we should not see dysfunction, but we should see difference. ${ }^{136}$ 
This is a helpful perspective that has been recognised in research with autistic people and those who live or work with them. In our own research on this issue, we considered how the notion of a disability might be understood discursively in relation to autism. ${ }^{137}$ Using focus groups with a range of stakeholders, including autistic adults, parents of autistic children, mental health practitioners, researchers, and service managers, we found that the notion of a disability is fluid, contestable, and socially constructed. For example, an autistic adult in the focus groups argued that autism is not a disability:

I'm a great believer that $\uparrow$ autism ${ }^{138}$ itself actually isn't a disability in any way at a::ll (.) in fact there are many areas where I would argue that my autism $>$ is a $s \uparrow$ trength. ${ }^{139}$

However, a mother of an autistic daughter, actively disagreed, noting that autism is a disability:

I kinda disagree $<$ because $(0.6)$ wouldn't you say that $(0.4)<$ some of th::e> the like from the $<$ triage $>$ of autism $(0.2)>$ the symptoms $<(.) \uparrow a::$ re a symptom of the condition which is autism.......So it is a disability. ${ }^{140}$

There was little agreement amongst participants as to whether autism constitutes a psychiatric disability as discussions permeated the boundaries of normality versus abnormality, disability versus ability, and medicalisation versus neurodiversity. While there was some acceptance that, clinically, categorisation and diagnosis were essential for support and service provision, and that some autistic people encountered more severe levels of difficulty than others, there was also an advocacy that autism was a fundamental characteristic of personhood and should not be characterised in limiting ways.

\section{Drawing Conclusions: Our Personal View of Autism in the Twentieth Century}

Our focus has predominantly been the evolution of autism throughout the twentieth century, exploring the various paradigmatic shifts that occurred and polar arguments that developed to influence our thinking around autism. However, these influences, research ideas, medical ideologies, genetic revolution, critical discourses, movements, and personal 
advocacies have all influenced our understanding of autism today. We now have a fractured view of a heterogeneous condition with a spectrum of characteristics, and of autistic people being different and reflecting a multitude of identities, views, opinions, and experiences. The twenty-first century is now plagued by the notion of an autism epidemic, and medicalised questions about where such an influx of autistic individuals has come from. This means that parents are thrown into a 'minefield of conflicting information'. ${ }^{141}$ Indeed, the volume of information is a confusing and time-consuming area for parents. ${ }^{142}$ Yet, in some ways, this has been positioned as hope for parents, as 'the first decade of the new century was a time of hope for many families, as parents told me they felt optimistic that science was on the verge of finally unravelling the mystery of their children's condition'. ${ }^{143}$

Such 'hope' and challenges related to autism are important as the 'epidemic' of the twenty-first century has become part of the medical rhetoric. There are few epidemiological studies of autism, but it is generally agreed that the prevalence currently stands at approximately $1 \%$ of the population. ${ }^{144}$ Similarly, in childhood, a total prevalence of 116.1 per 10,000 was presented. ${ }^{145}$ Baird et al. argued that the rates of autism are now much greater than was previously seen, and yet the reasons for such an increase in incidence are unclear. ${ }^{146}$ The consequences of this growth have meant that services are having to rapidly expand to meet the greater demands. ${ }^{147}$ Such an increase has however been controversial, as some have argued that it reflects an exaggeration of the existence of the condition, and others claiming it reflects the broader criteria. ${ }^{148}$ It is therefore arguably not a new scientific discovery, but a shifting cultural and social practice regarding the social construction as to what counts as normal. ${ }^{149}$

We conclude our chapter by presenting our perspective on this controversial issue and in so doing recognise the validity in different perspectives. In a personal and professional sense, we acknowledge our own experiences of autism. The lead author (O'Reilly) is an academic psychologist who has a brother diagnosed with autism, currently living in an institution due to the severity of his condition and the expanse of personal need. Furthermore, in addition to the academic position, O'Reilly also works as a research consultant for a Child and Adolescent Mental Health Service and therefore works alongside a multi-disciplinary team of mental health practitioners. The second author (Lester) is a former autism teacher in the USA, has a niece diagnosed with autism, and is now an academic working in educational autism research. The third 
author (Kiyimba) is an academic and chartered clinical psychologist, who specialises in trauma, and has worked professionally both with clients with autism, and as a clinical supervisor of mental health professionals working with autism, as well as supervising professionals who are autistic themselves. In outlining this personal position, we reflexively acknowledge that no text can ever be produced without influence and some imposition of the values and experiences of the writer, and our views and motivations are inspired and underpinned by our personal circumstances.

Thus, in our work on autism, we favour social constructionism as a guiding theoretical position, recognising the importance of language, and taking a child-centred and family-centred approach to research. We see the value of balancing the perspectives of psychiatrists, psychologists, other mental health professionals, autistic people, autistic advocates, families, and other stakeholders. The focus, for us, should be on meaning-making, that is, on the language used in different contexts and the impact that this has. In taking this social constructionist position, we do not deny the reality of autistic people or their families. This was eloquently expressed in a recent text by Thomas et al.:

This is not to deny the reality of mental health issues within people's lives, but rather to acknowledge that if we are to comprehend the ubiquity and impact of mental distress within a contemporary UK context, then we need to recognise the ways that particular types of scientific knowledge and particular narratives of distress have been invested with meaning and authority, and as such, have the potential to become tools for use in the pursuit of broader political agendas. ${ }^{150}$

The twentieth century saw many changes in the scientific and medical community understanding of autism. What we understand about autism is 'constantly in flux'. ${ }^{151}$ Autism as a condition has created much interest, amongst researchers, scientists, the public, and the media, and this is likely due to the multiplicity of meanings. ${ }^{152}$ We have argued that autism is a social construct. In so doing, we have recognised that for some autistic people, their autism is celebrated, but for other families it is distressing, and they struggle to cope with what they frame as adversity. ${ }^{153}$ We have woven a narrative that is congruent with the autonomy of those with lived experiences, have favoured a person-centred position, and explored alternative ways of thinking about the pervasive medicalised discourses that have constructed autism as a psychiatric disability. 
We have recognised that there are economic, institutional, and social consequences of adopting different social constructions of autism. ${ }^{154}$ Through our exploration of the different arguments, we have shown how the dominant ideas of the impaired autistic person have become reified through medical rhetoric and the genetic revolution. We argued that psychiatry and other mental health professions have an important place for autism but acknowledge that the embracing of biopsychosocial framings of autism within those fields is important. We also noted that social constructionism provides a way for easing some of the tensions and a focus on language sets autism centre stage and challenges narrow interpretations of normality. The neurodiversity movement will be considered in greater depth by Erika Dyck and Ginny Russell in Chapter 8.

Acknowledgements We are very grateful to two reviewers who provided very useful feedback on this chapter. We thank Professor Katherine Runswick-Cole, University of Sheffield (UK) and Professor Jason Lee, De Montfort University (UK).

\section{Notes}

1. Khalid Karim, Alvina Ali, and Michelle O'Reilly, A Practical Guide to Mental Health Problems in Children with Autistic Spectrum Disorder: 'It's Not Just Their ASD!' (London: Jessica Kingsley Publishers, 2014).

2. Majia Nadesan, Constructing Autism: Unravelling the 'Truth' and Understanding the Social (New York: Routledge, 2005).

3. Nadesan, Constructing Autism, 29.

4. Leo Kanner, "Autistic Disturbances of Affective Contact," Nervous Child 2 (1943): 217-250.

5. Steve Silberman, Neuro-Tribes (London: Allen \& Unwin, 2015).

6. Hans Asperger, "Die 'Autistischen Psychopathen' im Kindesalter [Autistic Psychopaths in Childhood]" (in German), Archiv für Psychiatrie und Nervenkrankheiten 117 (1944): 76-136.

7. Silberman, Neuro-Tribes.

8. Lorna Wing, "Language, Social and Cognitive Impairments in Autism and Severe Mental Retardation," Journal of Autism and Developmental Disorders 11, no. 1 (March 1981): 31-44.

9. Khalid Karim, "The Value of Conversation Analysis: A Child Psychiatrist's Perspective," in The Palgrave Handbook of Child Mental Health: Discourse and Conversation Studies, eds. Michelle O'Reilly and Jessica Nina Lester (Basingstoke: Palgrave Macmillan, 2015), 25-41. 
10. Michelle Lafrance and Suzanne McKenzie-Mohr, "The DSM and Its Lure of Legitimacy," Feminism and Psychology 23, no. I (February 2013): 119-140.

11. Bruno Bettelheim, The Empty Fortress (New York: Free Press, 1967).

12. Sometimes this is referred to as the 'icebox' mother.

13. Silberman, Neuro-Tribes.

14. Michelle O'Reilly and Jessica Nina Lester, Examining Mental Health Through Social Constructionism: The Language of Mental Health (Basingstoke: Palgrave, 2017).

15. Karim et al., A Practical Guide to Mental Health.

16. Linda Blum, "Mother-Blame in the Prozac Nation: Raising Kids with Invisible Disabilities," Gender and Society 21, no. 2 (April 2007): 202-226.

17. Debra Jackson and Judy Mannix, "Giving Voice to the Burden of Blame: A Feminist Study of Mothers' Experiences of Mother Blaming," International Journal of Nursing Practice 10, no. 4 (August 2004): $150-158$.

18. Jo Phelan, "Genetic Bases for Mental Illness-A Cure for Stigma?" Trends in Neurosciences 25 (2002): 430-431.

19. Karim, "The Value of Conversation Analysis." See also: Majia Nadesan, "Constructing Autism: A Brief Genealogy," in Autism and Representation, ed. Mark Osteen (New York: Routledge, 2008), 78-95.

20. Ibid.

21. Joseph Rey Francisco Assumpção, Carlos Bernad, Fusun Çuhadaroğlu, Bonnie Evans et al., "History of Child and Adolescent Psychiatry," in IACAPAP E-Textbook of Child and Adolescent Mental Health, ed. Joseph Rey (Geneva: International Association for Child and Adolescent Psychiatry and Allied Professions, 2015).

22. Kathleen Jones, Taming the Troublesome Child (Harvard: Harvard University Press, 1999).

23. Rey et al., "History of Child."

24. Karim, "The Value of Conversation Analysis."

25. Rudi Dallos and Ros Draper, An Introduction to Family Therapy: Systemic Theory and Practice (3rd edition) (Berkshire: Open University Press, 2010).

26. Karim, "The Value of Conversation Analysis."

27. American Psychiatric Association, Diagnostic and Statistical Manual of Mental Disorders (5th edition) (Washington: American Psychiatric Association, 2013).

28. Karim, "The Value of Conversation Analysis."

29. George Raines, "Comment: The New Nomenclature," American Journal of Psychiatry 109 (1953): 548-549. 
30. Shadia Kawa and James Giordano, "A Brief Historicity of the Diagnostic and Statistical Manual of Mental Disorders: Issues and Implications for the Future of Psychiatric Canon and Practice," Philosophy, Ethics and Humanities in Medicine 7, no. 2 (December 2012). https://doi. org/10.1186/1747-5341-7-2.

31. Edward Shorter, A History of Psychiatry: From the Era of the Asylum to the Age of Prozac (New York: Wiley, 1997).

32. Allan Horwitz, Creating Mental Illness (Chicago: University of Chicago Press, 2002).

33. Shorter, A History of Psychiatry.

34. Blashfield et al., "The Cycle of Classification."

35. Rick Mayes and Allan Horwitz, "DSM-III and the Revolution in the Classification of Mental Illness," Journal of the History of the Behavioural Sciences 41, no. 3 (Summer 2005): 249-267.

36. Shorter, A History of Psychiatry.

37. Ibid.

38. Fred Volkmar and Joe McPartland, "From Kanner to DSM-5: Autism as an Evolving Concept," Annual Review Clinical Psychology 10, no. 1 (December 2014): 193-212.

39. Lorna Wing and Judith Gould, "Severe Impairments of Social Interaction and Associated Abnormalities in Children: Epidemiology and Classification," Journal of Autism and Developmental Disorders 9, no. 1 (March 1979): 11-29.

40. Wing, "Language, Social and Cognitive Impairments."

41. David Giles, "DSM-V Is Taking Away Our Identity': The Reaction of the Online Community to the Proposed Changes in the Diagnosis of Asperger's Disorder," Health 18, no. 2 (June 2013): 179-195.

42. Tony Attwood, The Complete Guide to Asperger's Syndrome (London: Jessica Kingsley Publishers, 2007).

43. Blashfield et al., "The Cycle of Classification."

44. Ibid.

45. APA, Diagnostic and Statistical Manual.

46. Richard Bentall, Doctoring the Mind: Why Psychiatric Treatments Fail (London: Allen Lane, 2009).

47. We use the term "autistic community" to refer to individuals who self-identify as autistic and/or have a diagnosis of autism.

48. Giles, "DSM-V."

49. APA, Diagnostic and Statistical Manual.

50. Lorna Wing, Judith Gould, and Christopher Gillberg, "Autism Spectrum Disorders in the DSM-V: Better or Worse that the DSM-IV?" Research in Developmental Disabilities 32, no. 2 (March 2011): 768-773. 
51. Lorcan Kenny, Caroline Hattersley, Bonnie Molins et al., "Which Terms Should Be Used to Describe Autism? Perspectives from the UK Autism Community," Autism 20, no. 4 (May 2016): 442-462, 442.

52. Karim et al., A Practical Guide to Mental Health.

53. Kenny et al., "Which Terms Should Be Used?"

54. Joan Blaska, "The Power of Language: Speak and Write Using 'Person First," in Perspectives of Disability, ed. Mark Nagler (Palo Alto: Health Markets Research, 1993), 5-32.

55. Helena Halmari, "Political Correctness, Euphemism, and Language Change: The Case of 'People First'," Journal of Pragmatics 43, no. 3 (February 2011): 828-840. See also: John Robison, Be Different: Adventures of a Free-Range Aspergian with Practical Advice for Aspergians, Misfits, Families and Teachers (New York: Crown Publishing Group, 2011).

56. Joyce Davidson and Victoria Henderson, "'Coming Out' on the Spectrum: Autism, Identity and Disclosure," Social and Cultural Geography 11, no. 2 (March 2010): 155-170.

57. Karen Hagan, Discourses in Autism Assessment and Diagnosis (Unpublished PhD thesis, The Open University, Milton Keynes, 2018).

58. Kenny et al., "Which Terms Should Be Used?"

59. Jo Phelan, "Geneticization of Deviant Behaviour and Consequences for Stigma: The Case of Mental Illness," Journal of Health and Social Behaviour 46, no. 4 (2005): 307-322.

60. Sheila Mehta and Amerigo Farina, "Is Being 'Sick' Really Better? Effect of the Disease View of Mental Disorder on Stigma," Journal of Social and Clinical Psychology 16, no. 4 (1997): 405-419.

61. Carolyn Schanen, "Epigenetics of Autism Spectrum Disorders," Human Mol Genetics 15, no. 2 (2006): 138-150.

62. Elizabeth Pellicano, Adam Dinsmore, and Tony Charman, A Future Made Together: Shaping Autism Research in the UK (Centre for Research in Autism and Education Institute of Education, University of London, 2013).

63. Pellicano et al., A Future Made Together.

64. Rebecca Muhle, Stephanie Trentacoste, and Isabelle Rapin, "The Genetics of Autism," Paediatrics 113 (2004): 472-486.

65. Mitzi Waltz, "Autism=Death: The Social and Medical Impact of a Catastrophic Medical Model of Autistic Spectrum Disorders," Popular Narrative Media 1, no. l (2008): 13-24.

66. Michael Orsini and Joyce Davidson, "Introduction: Critical Autism Studies, Notes on an Emerging Field," in Worlds of Autism: Across the Spectrum of Neurological Difference, eds. Joyce Davidson and Michael Orsini (Minneapolis: University of Minnesota Press, 2013), 1-30. 
67. Elizabeth Pellicano and Mark Stears, "Bridging Autism, Science, and Society: Moving Toward an Ethically Informed Approach to Autism Research," Autism Research 4, no. 4 (August 2011): 271-282.

68. Pellicano et al., A Future Made Together.

69. Michelle O’Reilly, Khalid Karim, and Jessica Nina Lester, "Should Autism Be Classified as a Mental Illness/Disability? Evidence from Empirical Work," in The Palgrave Handbook of Child Mental Health; Discourse and Conversation Studies, eds. Michelle O'Reilly and Jessica Nina Lester, (Basingstoke: Palgrave Macmillan, 2015), 252-271.

70. Sami Timimi, J. Gardner, and B. McCabe, The Myth of Autism (London: Palgrave Macmillan, 2010).

71. Pellicano et al., "Bridging Autism."

72. Pellicano et al., A Future Made Together.

73. David Cooper, Psychiatry and Anti-psychiatry (London: Tavistock Publications, 1967).

74. Michael Staub, Madness Is Civilization (Chicago: University of Chicago Press, 2011).

75. Oliver Ralley, "The Rise of Anti-psychiatry: A Historical Review," History of Medicine Online (November 2012).

76. Michel Foucault, History of Madness (trans. J. Murphy and J. Khalfa) (London: Routledge, 2006).

77. Adrian Furnham, "Anti-psychiatry Movement: It Is 55 Years Since the Myth of Mental Illness: What Was That All About?" (2015). https:// www.psychologytoday.com/blog/sideways-view/201505/the-antipsychiatry-movement. Accessed 15 February 2016.

78. David Rissmiller and Joshua Rissmiller, "Evolution of the Anti-psychiatry Movement into Mental Health Consumerism," Psychiatric Services 57, no. 6 (June 2006): 863-866.

79. John Hopton, “The Future of Critical Psychiatry," Critical Social Policy 26, no. 1 (February 2006): 57-73.

80. Rob Whitley, "The Anti-psychiatry Movement: Dead, Diminishing, or Developing?” Psychiatric Services 63, no. 10 (October 2012): 1039-1041.

81. David Ingleby, ed., "Understanding 'Mental Illness'," in The Politics of Mental Health (Harmondsworth: Penguin, 1981), 23-71.

82. Phillip Thomas, "What Is Critical Psychiatry?" (2013). http://www. madinamerica.com/2013/01/what-is-critical-psychiatry/. Accessed 13 December 2016.

83. Phillip Thomas and Patrick Bracken, "Critical Psychiatry in Practice," Advances in Psychiatric Treatment 10, no. 5 (September 2004): 361-370.

84. Phillip Thomas, "What Is Critical Psychiatry?"

85. Duncan Double, "The Limits of Psychiatry," British Medical Journal 324, no. 13 (April 2002): 900-904. 
86. Til Wykes and Felicity Callard, "Diagnosis, Diagnosis, Diagnosis: Towards DSM-5," Journal of Mental Health 19, no. 4 (August 2010): 301-304.

87. Peter Conrad and Kristin Barker, "The Social Construction of Illness: Key Insights and Policy Implications," Journal of Health and Social Behaviour 51, S (2010): s67-s79.

88. Sarah Nettleton, The Sociology of Health and Illness (3rd edition) (Cambridge: Polity Press, 2013).

89. Thomas Szasz, "Psychiatry, Anti-psychiatry, Critical Psychiatry: What Do These Terms Mean?" Philosophy, Psychiatry, \& Psychology 17, no. 3 (January 2010): 229-232.

90. Jan Grue, "Discourse Analysis and Disability: Some Topics and Issues," Discourse and Society 22, no. 5 (August 2011): 532-546.

91. Stephen Gilson and Elizabeth DePoy, "Child Mental Health: A Discourse Community," in The Palgrave Handbook of Child Mental Health: Discourse and Conversation Studies, eds. Michelle O'Reilly and Jessica Nina Lester (Basingstoke: Palgrave Macmillan, 2015), 117-138.

92. Gil Eyal et al., The Autism Matrix: The Social Origins of the Autism Epidemic (Cambridge: Polity Press, 2010).

93. LaFrance and McKenzie-Mohr, "The DSM and Its Lure of Legitimacy."

94. Karen Ballard and Mary Ann Elston, "Medicalisation: A Multidimensional Concept," Social Theory and Health 3, no. 3 (July 2005): 228-241.

95. Tom Strong, "Brief Therapy and the DSM: 13 Possible Conversational Tensions," Journal of Brief Therapy 9, nos. 1-2 (2014): 1-12.

96. Allen Frances, Saving Normal: An Insider's Revolt Against Outof-Control Psychiatric Diagnosis, DSM-5, Big Pharma, and the Medicalization of Ordinary Life (New York: William Morrow, 2013).

97. Karim et al., A Practical Guide to Mental Health.

98. Steven Kapp et al., "Deficit, Difference, or Both? Autism and Neurodiversity," Developmental Psychology 49, no. I (January 2013): 59-71. See also: Russell Razzaque and Lisa Wood, "Open Dialogue and Its Relevance to the NHS: Opinions of NHS Staff and Service Users," Community Mental Health Journal 51, no. 8 (November 2015): 931-938.

99. Alicia Broderick and Ari Ne'eman, "Autism as Metaphor: Narrative and Counter Narrative," International Journal of Inclusive Education 12, nos. 5-6 (September 2008): 459-476.

100. Ruth Glynne-Owen, "Early Intervention and Autism: The Impact of Positivism and the Call for Change," International Journal of Children's Rights 18, no. 3 (January 2010): 405-416. 
101. Majia Nadesan, Constructing Autism: Unravelling the 'Truth' and Understanding the Social (New York: Routledge, 2005).

102. Jessica Nina Lester and Trena Paulus, “'That Teacher Takes Everything Badly': Discursively Reframing Non-normative Behaviours in Therapy Sessions," International Journal of Qualitative Studies in Education 27, no. 5 (2014): 641-666.

103. Mark Osteen, ed., "Autism and Representation: A Comprehensive Introduction," in Autism and Representation (New York: Routledge, 2008), 1-47.

104. Hagan, Discourses in Autism.

105. Nick Hodge and Katherine Runswick-Cole, "Problematising ParentProfessional Partnerships in Education," Disability and Society 23, no. 6 (October 2008): 637-647.

106. Dorothy Broom and Roslyn Woodward, "Medicalisation Reconsidered: Toward a Collaborative Approach to Care," Sociology of Health and Illness 18, no. 3 (1996): 357-378.

107. Erik Parens, “On Good and Bad Forms of Medicalization," Bioethics 27, no. 1 (January 2013): 28-35.

108. O'Reilly and Lester, Examining Mental Health.

109. Kristin Bumiller, "Quirky Citizens: Autism and the Anti-normalization of Politics," Annual Meeting of the American Political Science 33, no. 4 (June 2008): 967-991.

110. Juanne Clarke and Gudrun van Amerom, “'Surplus Suffering': Differences Between Organizational Understandings of Asperger's Syndrome and Those People Who Claim the 'Disorder'," Disability and Society 22, no. 7 (November 2007): 761-776.

111. Olga Solomon, "Body in Autism: A View from Social Interaction," in Language, Body and Health, eds. Paul McPherron and Vaidehi Ramanathan (Berlin, Germany: Walter de Gruyter, 2011), 105-144.

112. Nick Chown, "The Mismeasure of Autism: A Challenge to Orthodox Autism Theory," Autonomy, the Critical Journal of Interdisciplinary Autism Studies 1, no. 2 (May 2013): 1-10.

113. Jessica Nina Lester, Khalid Karim, and Michelle O'Reilly, “Autism Itself Actually Isn't a Disability: The Ideological Dilemmas of Negotiating a 'Normal' Versus 'Abnormal' Autistic Identity," Communication \& Medicine 11, no. 2 (November 2015): 139-152.

114. Kenny et al., "Which Terms Should Be Used?"

115. Ibid.

116. Thomas Armstrong, Neurodiversity: Discovering the Extraordinary Gifts of Autism, ADHD, Dyslexia, and Other Brain Differences (Cambridge: Da Capo, 2016). See also: Nobuo Masataka, "Implications of the Idea of Neurodiversity for Understanding the Origins of Developmental Disorders," Physics of Life Reviews 20 (November 2016): 85-108. 
117. Francisco Ortega, "The Cerebral Subject and the Challenge of Neurodiversity," BioSocieties 4, no. 4 (December 2009): 25-445.

118. Dana Baker, The Politics of Neurodiversity: Why Public Policy Matters (Boulder: Lynne Rienner, 2011).

119. Ortega, "The Cerebral Subject."

120. Pier Jaarsma and Stellan Welin, "Autism as a Natural Human Variation: Reflections on the Claims of the Neurodiversity Movement," Health Care Analysis 20, no. 1 (March 2012): 20-30.

121. Michael Orsini, "Autism, Neurodiversity and the Welfare State: The Challenges of Accommodating Neurological Difference," Canadian Journal of Political Science 45, no. 4 (December 2012): 805-827.

122. Jaarsma and Welin, "Autism as a Natural Human Variation."

123. Andrew Fenton and Timothy Krahn, "Autism, Neurodiversity and Equality Beyond the 'Normal'," Journal of Ethics in Mental Health 2, no. 2 (November 2007): 1-6.

124. Katherine Runswick-Cole, “'Us' and 'Them': The Limits and Possibilities of a 'Politics of Neurodiversity' in Neoliberal Times," Disability \& Society 29, no. 7 (May 2014): 1117-1129.

125. Charlotte Brownlow, "Presenting the Self: Negotiating a Label of Autism," Journal of Intellectual and Developmental Disability 35, no. 1 (March 2010): 14-21.

126. Baker, The Politics of Neurodiversity; Kapp et al., "Deficit, Difference, or Both?"

127. Pellicano and Stears, "Bridging Autism."

128. Waltz, "Autism=Death."

129. Ari Ne'eman, "The Future (and the Past) of Autism Advocacy, or Why the ASA's Magazine, The Advocate Wouldn't Publish This Piece," Disability Studies Quarterly 30, no. I (February 2010). See also: Runswick-Cole, "'Us' and 'Them'."

130. Brigitte Chamak, "Autism and Social Movements: French Parents' Associations and International Autistic Individuals' Organizations," Sociology of Health and Illness 30, no. 1 (2008): 76-96.

131. Simon Baron-Cohen, "Editorial Perspective: Neurodiversity-A Revolutionary Concept for Autism and Psychiatry," Journal of Child Psychology and Psychiatry 58, no. 6 (May 2017): 744-747.

132. Kapp et al., "Deficit, Difference, or Both?"

133. Orsini, "Autism, Neurodiversity."

134. Baron-Cohen, "Editorial Perspective."

135. Jaci Huws and Robert Jones, "Diagnosis, Disclosure, and Having Autism: An Interpretative Phenomenological Analysis of the Perceptions of Young People with Autism," Journal of Intellectual and Developmental Disability 33, no. 2 (2008): 99-107. 
136. Meng-Chuan Lai et al., "Subgrouping the Autism 'Spectrum': Reflections on DSM-5," PLoS Biology 11, no. 4 (April 2013): el001544.

137. Lester et al., "Autism Itself Actually Isn't a Disability."

138. The symbols in these quotations of data are from the Jefferson CA system.

139. Ibid., 143.

140. Ibid., 144.

141. Silberman, Neuro-Tribes, 13.

142. Michelle O'Reilly, Khalid Karim, and Jessica Nina Lester, "Separating 'Emotion' from 'the Science': Exploring the Perceived Value of Information for Parents and Families of Children with ASD," Clinical Child Psychology and Psychiatry 20, no. 3 (April 2015): 500-514.

143. Silberman, Neuro-Tribes, 12.

144. Traloch Brugha et al., Autism Spectrum Disorders in Adults Living in Households Throughout England: Report from the Adult Psychiatric Morbidity Survey 2007 (The NHS Information Centre for Health and Social Care, 2009).

145. Gillian Baird, Emily Simonoff, Andrew Pickles, et al., "Prevalence of Disorders of the Autism Spectrum in a Population Cohort of Children in South Thames: The Special Needs and Autism Project (SNAP)," Lancet 368, no. 9531 (2006): 210-215.

146. Ibid.

147. Karim et al., A Practical Guide to Mental Health.

148. Eyal et al., The Autism Matrix; Sami Timimi, "Autism Is Not a Scientifically Valid or Clinically Useful Diagnosis," British Medical Journal 343 (August 2011): d5105; Wykes and Callard, "Diagnosis, Diagnosis, Diagnosis."

149. Timimi et al., The Myth of Autism.

150. Felicity Thomas et al., "Moral Narratives and Mental Health: Rethinking Understandings of Distress and Healthcare Support in Contexts of Austerity and Welfare Reform," Palgrave Communications 4, no. 39 (April 2018): 2.

151. Kenny et al., "Which Terms Should Be Used?"

152. Orsini and Davidson, "Critical Autism Studies."

153. Hodge and Runswick-Cole, "Problematising Parent-professional Partnerships."

154. Jessica Nina Lester and Michelle O'Reilly, "Repositioning Disability in the Discourse of Our Times: A Study of the Everyday Lives of Children with Autism," in Education, Equity, and Economy, eds. George Noblit and William Pink (London: Springer, 2016), 133-160. 
Open Access This chapter is licensed under the terms of the Creative Commons Attribution 4.0 International License (http://creativecommons.org/licenses/ by $/ 4.0 /)$, which permits use, sharing, adaptation, distribution and reproduction in any medium or format, as long as you give appropriate credit to the original author(s) and the source, provide a link to the Creative Commons license and indicate if changes were made.

The images or other third party material in this chapter are included in the chapter's Creative Commons license, unless indicated otherwise in a credit line to the material. If material is not included in the chapter's Creative Commons license and your intended use is not permitted by statutory regulation or exceeds the permitted use, you will need to obtain permission directly from the copyright holder.

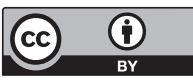

